\title{
Evaluation of the TSI Aerosol Impactor 3306/3321 System Using a Redesigned Impactor Stage With Solution and Suspension Metered-dose Inhalers
}

Submitted: June 17, 2005; Accepted: December 5, 2005; Published: March 10, 2006

Julie A. Harris, ${ }^{1}$ Stephen W. Stein, ${ }^{2}$ and Paul B. Myrdal ${ }^{1}$

${ }^{1}$ College of Pharmacy, University of Arizona, Tucson, AZ

${ }^{2} 3 \mathrm{M}$ Drug Delivery Systems, Early Pharmaceutics and Technology Laboratory, St Paul, MN

\begin{abstract}
The purpose of this research was to evaluate a redesigned impactor stage for the TSI Model 3306 Impactor Inlet with nozzles adjusted to obtain a target cut-point of $4.7 \mu \mathrm{m}$. It has been determined that the previous cut-point used in the Model 3306 was nominally closer to $4.14 \mu \mathrm{m}$, thus potentially impacting the characterization of aerosol mass. The reassessment of the Model 3306 was performed on 4 solution and 2 suspension metered-dose inhaler (MDI) formulations. The redesigned impactor stage resulted in a $5 \%$ to $6 \%$ increase in aerosol mass when compared with the previous impactor stage for the products Ventolin-HFA, Proventil-HFA, and 2 cyclosporin solution formulations with high ethanol concentrations $(15 \% \mathrm{wt} / \mathrm{wt})$. For the formulations with low ethanol concentrations $(3 \% \mathrm{wt} / \mathrm{wt})$, minimal differences were observed between the 2 cut-points. In addition, this study reevaluated the requirement of a vertical inlet extension length when using the TSI 3306/3321 system with the redesigned cut-point. It was shown that the use of a $20-\mathrm{cm}$ extension provides mass and aerosol size distributions that are comparable to the Andersen 8-stage Cascade Impactor, for both solution and suspension MDIs. This work indicates that the TSI 3306/3321 system is suitable for preformulation studies of both suspension and solution MDI systems.
\end{abstract}

KEYWORDS: aerosols, metered-dose inhalers, particle sizer, size distribution.

\section{INTRODUCTION}

The aerodynamic diameter of a medicinal aerosol has a direct bearing on the ability of the aerosolized drug to deposit in the lungs and is thus an important parameter when developing metered-dose inhalers (MDIs). Analysis of the particle distribution from a pressurized MDI is typically performed using a multi-stage cascade impactor equipped with United States Pharmacopeia/European Pharmacopeia

Corresponding Author: Julie A. Harris, University of

Arizona, 1703 East Mabel St, Tucson, AZ 85719.

Tel: (520) 626-3847; Fax: (520) 626-4063;

E-mail: harris@pharmacy.arizona.edu
(USP/Ph Eur) induction port. The Andersen 8-stage Cascade Impactor (ACI) (Thermo Andersen, Smyrna, GA) is a standard compendial method for particle size assessment. Testing with the ACI allows for the mass and particle size distribution of the aerosolized drug to be determined directly through chemical analysis of each impaction stage.

While reliable, the ACI is a labor-intensive test method, especially for early product development. As a result, there is an ongoing interest in the development of more efficient techniques for aerosol characterization. ${ }^{1,2}$ Several researchers have evaluated laser diffraction as a potential method for characterizing aerosols. For continuously nebulized solutions, correlations between laser diffraction and cascade impaction can be obtained, provided environmental conditions are controlled. ${ }^{3-6}$ Relationships between laser diffraction and cascade impaction for MDI systems are more challenging owing to the dynamic liquid-vapor regime surrounding the aerosolized particles. ${ }^{7-9}$ Phase Doppler particle size analysis has also been evaluated for aqueous aerosols ${ }^{10}$; however, as with laser diffraction, neither method directly quantifies the drug present in the aerosol.

Recent interest has centered on the TSI 3306/3321 system (TSI Inc, Particle Instruments, Shoreview, MN), which represents an efficient tool for direct particle size measurement, while affording the ability to determine drug mass. ${ }^{1,2,11}$ The TSI Model 3321 aerodynamic particle sizer (APS) aerosol spectrometer, is a real-time aerodynamic particle size analyzer based on time-of-flight (TOF) analysis. This laserbased particle sizing instrument measures the mass median aerodynamic diameter (MMAD) of aerosol particles based on the particle's velocities immediately downstream of a flow-accelerating nozzle. ${ }^{1}$ The Model 3321 can be integrated with the TSI Model 3306 single-stage impactor inlet. The use of a 4.7- $\mu \mathrm{m}$ impaction stage allows for the quantification of the fine particle mass of the aerosolized drug less than $4.7 \mu \mathrm{m}\left(\mathrm{FPM}_{4.7 \mu \mathrm{m}}\right)$.

In previous reports the use of different vertical inlet extension lengths $(0,20,40 \mathrm{~cm})$ were evaluated with the TSI 3306/3321 system for solution aerosols. ${ }^{2,12}$ The purpose of an extension is to allow a longer physical path for the droplets to travel before reaching the impactor jet, thus facilitating particle evaporation. The degree to which the extension length affects the droplet distribution depends on 
the formulation. Formulations with minimal or no semivolatile constituents will likely be unaffected. Those formulations containing significant semivolatile compositions are much more likely to be affected. These past studies demonstrated that the TSI 3306/3321 system can be used to obtain $\mathrm{FPM}_{4.7 \mu \mathrm{m}}$ values similar to the ACI. However, it has recently been determined that the original cut-point supplied in the Model 3306 design was smaller than the labeled $4.7 \mu \mathrm{m}$. As a result, the quantification of $\mathrm{FPM}_{4.7 \mu \mathrm{m}}$ may have been inaccurate, most notably for MDI formulations with particle size distributions approaching the cut-point.

The objective of this investigation was to quantify the differences between the 2 different cut-points used with the Model 3306 and to reevaluate the utility of inlet extensions when comparing $\mathrm{FPF}_{4.7 \mu \mathrm{m}}$ data to those obtained from ACI testing. In addition to varied solution formulations, this study demonstrates the feasibility of using the TSI $3306 / 3321$ system for characterizing suspension MDIs.

\section{MATERIALS AND METHODS}

\section{Formulations}

Two suspension products, Proventil-HFA (containing ethanol and surfactant) and Ventolin-HFA (containing no cosolvent or surfactant) were obtained from a commercial pharmacy. Four experimental solution MDI formulations made with varying cyclosporine (CSP) and ethanol concentrations were also evaluated and are displayed in Table 1.

\section{ACI}

The ACI was operated at a flow rate of $28.3 \mathrm{~L} / \mathrm{min}$. The ACI contained stainless steel collection plates, which were coated for the suspension formulation Ventolin-HFA. A microfiber filter was placed after the bottom impaction stage. Each canister was shaken and then primed by actuating 3 times to waste. Each MDI was shaken prior to use and actuated 5 times, with the mouthpiece of the inhaler coupled on axis with the entry to the induction port ( $\mathrm{n}=3$ vials). Flow through the ACI was maintained for an additional 30 seconds following the final actuation. The impactor was

Table 1. The 4 Cyclosporin Measured Dose Inhaler Solution Formulations Evaluated With the TSI 3306/3321 System and Andersen 8-stage Cascade Impactor

\begin{tabular}{lccc}
\hline Formulation & $\begin{array}{c}\text { Cyclosporin } \\
(\% \mathrm{wt} / \mathrm{wt})\end{array}$ & $\begin{array}{c}\text { Ethanol } \\
(\% \mathrm{wt} / \mathrm{wt})\end{array}$ & $\begin{array}{c}\text { HFA-134a } \\
(\% \mathrm{wt} / \mathrm{wt})\end{array}$ \\
\hline A & 0.1 & 3 & 96.9 \\
$\mathrm{~B}$ & 0.1 & 15 & 84.9 \\
$\mathrm{C}$ & 2 & 3 & 95 \\
$\mathrm{D}$ & 2 & 15 & 83 \\
\hline
\end{tabular}

disassembled and the amount of drug (active pharmaceutical ingredient) was recovered quantitatively from the stem, actuator, inlet, collection plates, and filter. Samples were then assayed by high-performance liquid chromatography (HPLC)-UV spectrophotometry at a wavelength of $276 \mathrm{~nm}$ for albuterol sulfate and $210 \mathrm{~nm}$ for CSP. The HPLC system consisted of a Waters 2690 separation module (Waters, Milford, MA) coupled with a Waters 2487 dual wavelength absorbance detector. Sample analysis was performed by a reverse-phase HPLC assay, using a $150 \times 4.6 \mathrm{~mm}, 5 \mu \mathrm{m}$ Apollo Silica column for albuterol sulfate, and a $150 \times 3.2 \mathrm{~mm}$, $5 \mu \mathrm{m}$ Alltech C18 platinum column for CSP. The mobile phase for CSP was 70\% acetonitrile and 30\% water at a flow rate of $1.0 \mathrm{~mL} / \mathrm{min}$. The mobile phase for albuterol sulfate was $82 \%$ acetonitrile and $18 \% 0.1 \%$ ammonium acetate $(\mathrm{pH} \mathrm{3.0)}$ at a flow rate of $0.8 \mathrm{~mL} / \mathrm{min}$.

\section{TSI Model 3306/3321 System}

The Model 3306 and Model 3321 were operated together. Aerosol presentation to the Model 3306 (Figure 1) is through a $U S P / P h$ Eur inlet, at a flow rate of $28.3 \mathrm{~L} / \mathrm{min}$, and past a single-stage impactor. For this study, the target cut-point of the impactor stage was $4.7 \mu \mathrm{m}$, thereby allowing for the collection of a fine particle mass less than $4.7 \mu \mathrm{m}\left(\mathrm{FPM}_{4.7 \mu \mathrm{m}}\right)$ from the filter. The larger aerosol particles that do not flow through to the filter are collected on the impaction plate. Vertical extensions of 20 and $40 \mathrm{~cm}$, when used, were inserted between the USP/Ph Eur inlet and the Model 3306. A small portion of the aerosol that penetrates through the USP/Ph Eur inlet $(0.2 \%$ of the sample) is sampled isokinetically for size measurement via the Model 3321. The Model 3321 analyzes particles as they pass individually through the measurement zone, where their aerodynamic size is determined by TOF. For testing, each vial was shaken and then primed by actuating 3 times to waste. Five actuations were delivered for each test, and 3 tests were conducted for each vial. The mass median aerodynamic diameter (MMAD) was calculated using the TSI software, Aerosol Instrument Manager, Rev B (2002). The plate and filter were assayed via HPLC-UV, as described in the ACI section.

\section{Filter Percentage}

In order to quantify the effects that cut-point and extension length differences have on the aerosol classification via the Model 3306, it is necessary to evaluate the relative changes in the plate and filter depositions. To this end the filter percentage (Filter \%) can be defined as:

$$
\text { Filter } \%=\left(\frac{\text { Filter }}{\text { Filter }+ \text { Plate }}\right) \times 100
$$




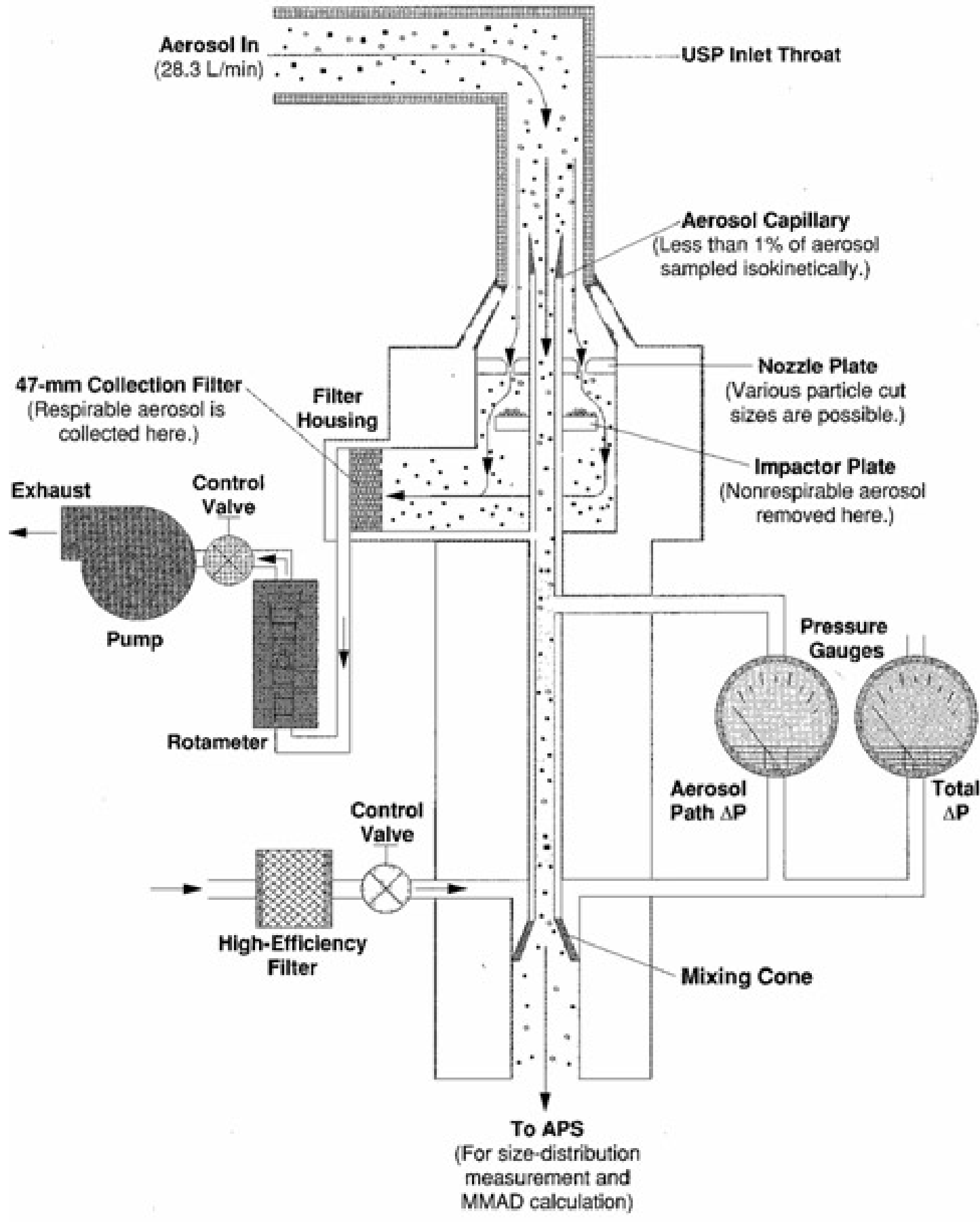

Figure 1. A schematic diagram of the Model 3306, where the aerosol enters through the USP throat inlet. Particles larger than $4.7 \mu \mathrm{m}$ are impacted on the impactor plate (nonrespirable) and particles smaller than $4.7 \mu \mathrm{m}$ are collected on the filter (respirable). Courtesy of TSI Inc.

where Filter represents the aerosol mass that passes the impaction plate $\left(\mathrm{FPM}_{4.7 \mu \mathrm{m}}\right)$ and the Plate represents the mass that is deposited on the impaction plate. The Filter \% describes the percentage $\mathrm{FPM}_{4.7 \mu \mathrm{m}}$ of the aerosol that is presented to the impactor jets. This quantification allows for the performance of the impactor stage to be evaluated in isolation from the stem, actuator, or USP/Ph Eur inlet. This method is reasonable since the performance of the impactor stage should be independent of deposition in the stem, ac- tuator, and $U S P / P h$ inlet. The plate percentage is correspondingly $100 \%$ minus the Filter $\%$ and is not presented.

\section{Fine Particle Fraction FPF $_{4.7} \mu \mathrm{m}$}

The $\mathrm{FPF}_{4.7 \mu \mathrm{m}}$ has historically been used as guidance for the therapeutic portion of the inhaled drug mass capable of reaching the airways of the respiratory tract. The $\mathrm{FPF}_{4.7 \mu \mathrm{m}}$ is defined as the $\mathrm{FPM}_{4.7 \mu \mathrm{m}}$ divided by the total amount of 
drug that exits the MDI mouthpiece. For the TSI 3306/ 3321 system, $\mathrm{FPF}_{4.7 \mu \mathrm{m}}$ can be determined by the following equation:

$F P F_{4.7 \mu m}^{T S I}=\left(\frac{F P M_{4.7 \mu m}}{U S P / P h \text { Eur }+ \text { extension }(s)+\text { plate }+F P M_{4.7 \mu m}}\right) \times 100$

where the USP/Ph Eur inlet and extension(s) represent the amount of drug deposited on each. In general, the amount quantifiable on the extensions has been found to be very small or negligible. ${ }^{12}$ In this study, detectable quantities of drug were found on only 24 of the 72 experiments (solution MDI formulations $\mathrm{C}$ and $\mathrm{D})$ performed using the 20- or $40-\mathrm{cm}$ extension on the TSI. The average was $1.75 \%$ of the total drug delivered.

Correspondingly, for the ACI, total drug recovered on stages 3 through 7 and filter is considered to be the $\mathrm{FPM}_{4.7 \mu \mathrm{m}}$, giving the following equation:

$F P F_{4.7 \mu m}^{A C I}=\left(\frac{F P M_{4.7 \mu m}}{U S P / P h \text { Eur }+ \text { stage } s_{0-2}+F P M_{4.7 \mu m}}\right) \times 100$

where stages 0 to 2 are stages 0,1 , and 2 of the ACI. The $\mathrm{FPF}_{4.7 \mu \mathrm{m}}$ was determined for the 4 solution formulations and 2 suspension products for both the TSI 3306/3321 system and the ACI.

\section{Impactor Stage Cut-Point Calculations}

For a given impactor stage, the particle collection efficiency is highly dependent on the Stokes' number $\left(\mathrm{Stk}_{50}\right)$ for that particular particle size. The collection efficiency curve for a given impactor stage is a function of the Stokes' number and can be numerically or experimentally determined. ${ }^{13,14}$ The most descriptive value of an impactor stage is the Stokes' number at which $50 \%$ of the particles impact and are collected, $\mathrm{Stk}_{50}$. The aerodynamic cut-point of a stage, $\mathrm{d}_{\mathrm{a} 50}$, is the aerodynamic particle diameter at which $\mathrm{Stk}=$ $\mathrm{Stk}_{50 .}{ }^{14}$ It is possible to solve for the aerodynamic cut-point, $\mathrm{d}_{\mathrm{a} 50}$, of a stage using the following equation:

$$
d_{a 50}=\sqrt{\frac{9 S t k_{50} \eta \pi D j 3 N}{4 \rho_{p} Q C_{c}}}
$$

where $\eta$ is the viscosity of the air; $D_{j}$ is the jet diameter; $\mathrm{N}$ is the total number of jets on the impactor stage; $\rho_{\mathrm{p}}$ is the density of the particle; $\mathrm{Q}$ is the total flow rate through the impactor stage; and $\mathrm{C}_{\mathrm{c}}$ is the Cunningham slip correction, which is a function of particle size. Equation 4 can be used to estimate the cut-point of various impactor stages as a function of nozzle diameter. In order to do this, it is first necessary to have an estimate of the $\mathrm{Stk}_{50}$ of the stage. ${ }^{15,16}$ The manufacturer's reported cut-point and target hole diameter (new cut-point value) were used to estimate a $\mathrm{Stk}_{50}$ value of 0.3924 for the Model 3306. Next, the "old cutpoint" aerodynamic diameter, $\mathrm{d}_{\mathrm{a} 50}$, was estimated by substituting the calculated $\mathrm{Stk}_{50}$ number and the actual jet diameter of the old design impactor stage into Equation 4. The old cut-point for the Model 3306 was calculated to be $\sim 4.14 \mu \mathrm{m}$.

\section{RESULTS AND DISCUSSION}

\section{The Influence of Impactor Stage Cut-Point on Filter \%}

The impact that the erroneous Model 3306 cut-point had on estimation of $\mathrm{FPM}_{4.7 \mu \mathrm{m}}$ was determined experimentally for both solution and suspension MDIs and is described in the following sections.

\section{Solution Formulations}

The Filter \% for the various CSP solution formulations are shown in Figures 2 and 3. Figure 2 demonstrates that for low concentrations of drug and ethanol (A: $0.1 \% \mathrm{wt} / \mathrm{wt}$ CSP, 3\% wt $/ \mathrm{wt}$ ethanol) the average increase in Filter $\%$ for the new cut-point is a modest $0.57 \%,(P=.73)$ owing to the relatively small aerosol distribution produced from the formulation $(\mathrm{MMAD}=0.93$, geometric standard deviation $[\mathrm{GSD}]=1.68$, see Table 2). The influence that the inlet

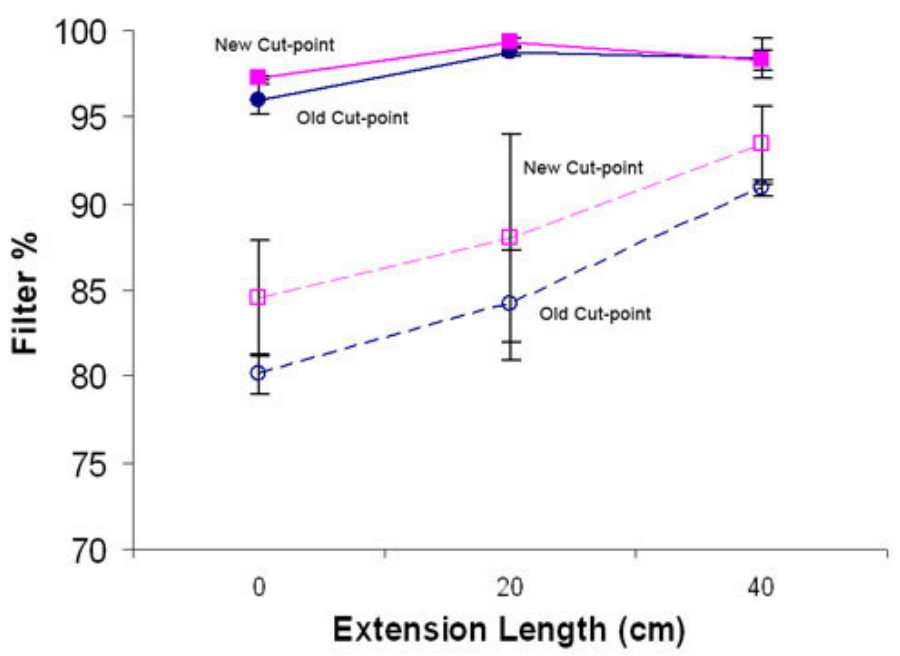

Figure 2. Percentage fine particle mass of aerosol that enters the Model 3306 versus extension length for old and new cut-points using formulations (A) $0.1 \%$ cyclosporin with $3.0 \%$ ethanol (solid symbols), and (B) $0.1 \%$ cyclosporin with $15.0 \%$ ethanol (open symbols). 
AAPS PharmSciTech 2006; 7 (1) Article 20 (http://www.aapspharmscitech.org).

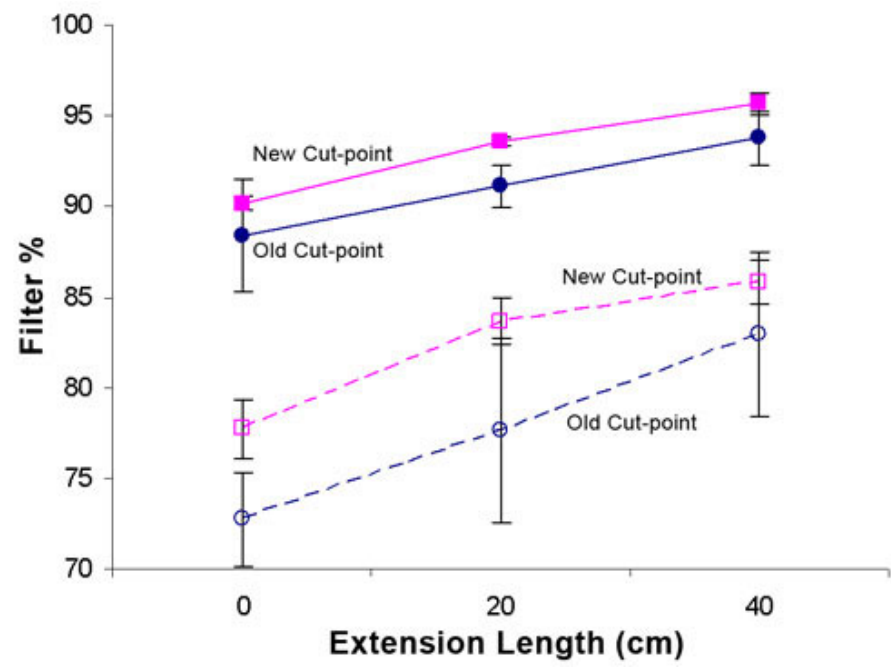

Figure 3. Percentage fine particle mass of aerosol that enters the Model 3306 versus extension length for old and new cut-points using formulations (C) 2\% cyclosporin with 3\% ethanol (solid symbols), and (D) $2 \%$ cyclosporin with $15 \%$ ethanol (open symbols).

extension length had on the Filter \% will be discussed later. However, for formulation $\mathrm{B}$, (that has the same low drug concentration, but a higher ethanol content, $15 \% \mathrm{wt} / \mathrm{wt}$ ) differences between cut-points are slightly more evident $(P=.07)$ (Figure 2). While the residual particle distribution determined from the Model 3321 for formulation B (MMAD $=1.11 \mu \mathrm{m}, \mathrm{GSD}=1.61$; see Table 2$)$ is nearly the same as that of formulation $\mathrm{A}$, it is evident that the aerosol passing the Model 3306 was not completely dry, resulting in a larger intermediate particle size distribution. Correspondingly, the new cut-point on the Model 3306 resulted in a $4.2 \%$ average increase in Filter $\%$ as compared with the old cut-point (whereas formulation A showed virtually no difference). Formulations $\mathrm{C}$ and D (Figure 3) had a higher nonvolatile concentration $(2 \% \mathrm{wt} / \mathrm{wt})$, which results in a larger particle size (MMAD of 2.66 and $3.05 \mu \mathrm{m}$, respectively; see Table 2) and a lower Filter \% in general, owing to the larger particle size distribution. Formulations $\mathrm{C}$ and $\mathrm{D}$ also show an increase in Filter \% for the new cut-point with each extension length. These formulations were more sensitive to the exact cut-point of the Model 3306 since a greater portion of the aerosol mass was between $4.14 \mu \mathrm{m}$ and $4.7 \mu \mathrm{m}$. The aerosol in this size range would likely have been collected on the impactor plate for the old (erroneous) cut-point but would likely not have been collected on the impactor plate when the new cut-point on the Model 3306 was used. The average increase in Filter \% for the new cut-point for formulations $\mathrm{C}$ and $\mathrm{D}$ are $2.8 \%$ and $6.0 \%$, respectively ( $P$ value $0.01,0.002$, respectively). Once again, the formulation with $15 \%$ ethanol had a lower Filter \% than the $3 \%$ ethanol formulation. This result may be explained by the slightly increased residual particle MMAD (Table 2), along with the fact that the size of the droplets was possibly larger owing to incomplete evaporation of the ethanol as the droplets pass through the impactor stage.

In general, it is clear that the new cut-point consistently resulted in a higher Filter \%, which is in alignment with the cut-point calculations. In addition, Figures 2 and 3 reveal an increase in Filter \% with an increase in extension length, which will be discussed later.

\section{Suspension Formulations}

The effect of cut-point differences were also evaluated using suspension MDI formulations. The Filter \% for VentolinHFA and Proventil-HFA are shown in Figures 4 and 5, respectively. The average increase in Filter \% for the new cut-point using Ventolin-HFA was $5.5 \%,(P=.01)$, while the percentage increase for Proventil-HFA averaged 6\% $(P=.002)$. Based on the particle size distributions for both Ventolin-HFA and Proventil-HFA (MMAD $=2.16$, GSD $=$ 1.51 and $\mathrm{MMAD}=2.26, \mathrm{GSD}=1.89$, respectively), this trend is consistent with that observed for the solution formulations $\mathrm{C}$ and $\mathrm{D}$. The Filter \% differences between old and new cut-point for both solution and suspension MDI formulations illustrate that the old cut-point has a smaller diameter, which resulted in a modest underestimation of the Filter \% measured by the Model 3306.

Table 2. A Comparison of Size Distribution Measurements for 4 Cyclosporin Measured Dose Inhaler Solutions and 2 Suspensions Using the 20-cm Extension and New Cut-Point for the TSI 3306/3321 System Formulation*

\begin{tabular}{lcccr}
\hline Formulation & ACI & ACI & APS & APS \\
GSD
\end{tabular}

*ACI indicates Andersen 8-stage Cascade Impactor; MMAD, mass median aerodynamic diameter; APS, aerodynamic particle sizer; and GSD, geometric standard deviation. 
AAPS PharmSciTech 2006; 7 (1) Article 20 (http://www.aapspharmscitech.org).

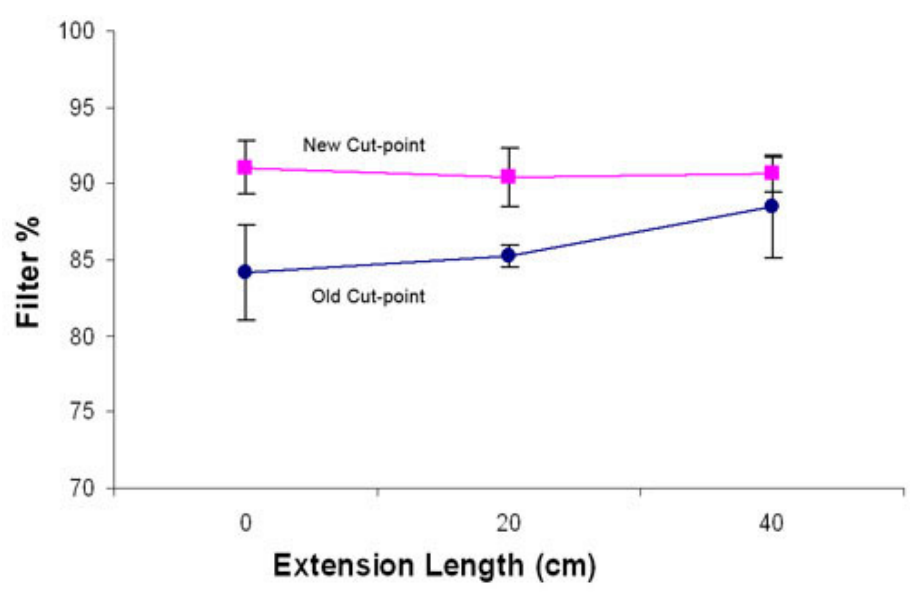

Figure 4. Percentage fine particle mass of aerosol that enters the Model 3306 versus extension length for old and new cut-points using Ventolin-HFA suspension formulation.

\section{Influence of Extension Length on Filter \%}

\section{Solution Formulations}

In addition to investigating cut-point differences, this study reevaluated the appropriate use of an inlet extension based on formulation content for solution and suspension MDIs with the new cut-point on the Model 3306. Previous published work has shown that an extension is necessary for solution MDIs with higher concentrations of ethanol. ${ }^{2,12}$ For the solution MDIs in this study, as the vertical extension length increased from 0 to $40 \mathrm{~cm}$, the Filter \% also increased (Figures 2 and 3). The additional extension lengths had minimal effect on the particle distribution for formulation A (low drug and ethanol concentration) with an observed Filter \% increase of $2 \%$ from 0 to $20 \mathrm{~cm}$ and no additional increase from 20 to $40 \mathrm{~cm}$ (Figure 2). Formulation C, containing the same ethanol concentration as formulation A (3\%) and higher drug concentration (2\%), had a slightly higher Filter \% increase (5\%) when going from 0 to $40 \mathrm{~cm}$ (Figure 3). The increase in extension length had the greatest effect on formulations B and D, which both contained $15 \%$ ethanol. These formulations had a total increase of $\sim 8 \%$ in Filter $\%$ as the vertical extension length increased from 0 to $40 \mathrm{~cm}$.

\section{Suspension Formulations}

This work also examined commercial suspension formulations with varying ethanol concentrations using the different inlet extension lengths. The Filter \% for Ventolin-HFA, which does not contain a semivolatile cosolvent, was not significantly affected by the use of extension lengths (Figure 4). However Proventil-HFA, which does contain ethanol in the formulation, had a significant increase in Filter \% (10\%) as a function of extension length (Figure 5). As was the case for solution MDIs, the degree to which the extension length affects the Filter \% for suspension MDIs depends on the nonvolatile composition in the formulation. As the vertical extension length increased from 0 to $40 \mathrm{~cm}$, Proventil-HFA showed a clear increase in Filter \%, whereas Ventolin-HFA did not. These trends were seen for both the old and new cut-points.

\section{Comparison of TSI 3306/3321 System with the ACI}

The TSI 3306/3321 system, an attractive instrument for rapid screening in early product development, was compared with results obtained via the ACI. The cut-point of stage 2 on the ACI was assumed to be $\sim 4.7 \mu \mathrm{m}$ (the nominal cutpoint as indicated by the manufacturer). The optimal way to determine the actual cut-point of any given stage is to determine the collection efficiency curve of the stage using monodisperse reference particles. However, this is very labor intensive and was not used for this investigation. The collection efficiency curve of the ACI has been previously described. ${ }^{17}$ The exact cut-point of any given ACI stage has been shown to vary depending on the exact dimensions of the nozzles on the stage. ${ }^{18}$

The redesigned cut-point, along with the $20-\mathrm{cm}$ extension, was used to analyze the utility of the TSI 3306/3321 system compared with the ACI for both solution and suspension MDI formulations. The $\mathrm{FPF}_{4.7 \mu \mathrm{m}}$ and particle size results were analyzed in order to evaluate comparability of the 2 systems.

\section{Fine Particle Fraction $\left(F P F_{4.7 \mu m}\right)$}

The $\mathrm{FPF}_{4.7 \mu \mathrm{m}}$ was determined for the 4 solution formulations and 2 suspension products for both the TSI 3306/ 3321 APS system and ACI. Figure 6 compares the $\mathrm{FPF}_{4.7 \mu \mathrm{m}}$ determined for each formulation from the ACI to that from the TSI 3306/3321 system using the $20-\mathrm{cm}$ extension and the new cut-point. Only 1 (Formulation $\mathrm{C}$ ) of the 4 solution

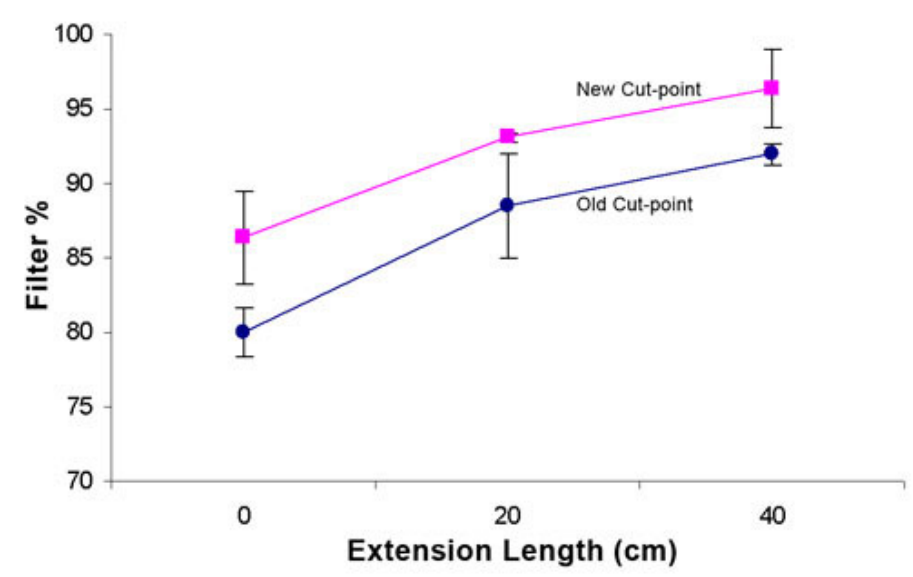

Figure 5. Percentage fine particle mass of aerosol that enters the Model 3306 versus extension length for old and new cut-points using Proventil-HFA suspension formulation. 


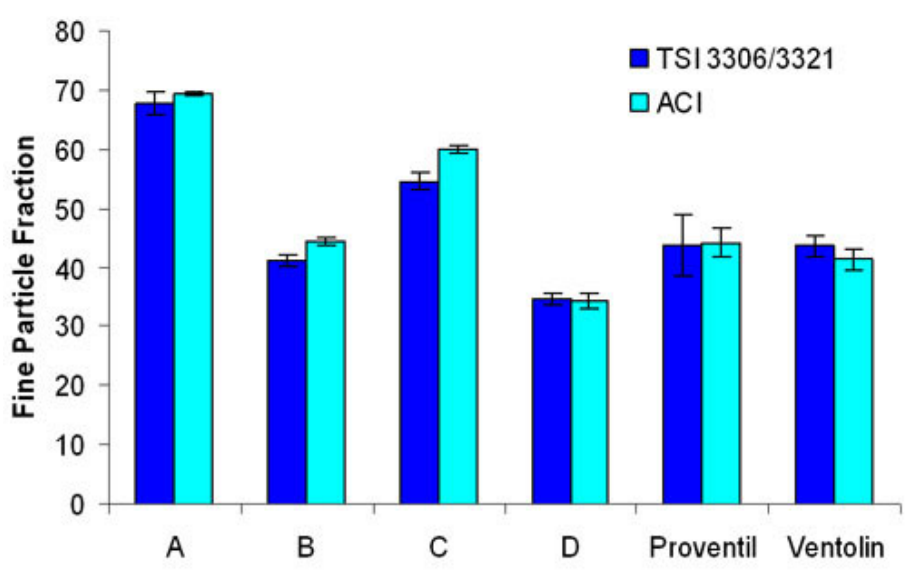

Figure 6. Characterization of fine particle fraction $\left(\mathrm{FPF}_{4.7 \mu \mathrm{m}}\right)$ particle distribution using the new cut-point and $20-\mathrm{cm}$ extension for solution and suspension formulations on the TSI 3306/3321 system and ACI.

formulations had $\mathrm{FPF}_{4.7} \mu \mathrm{m}$ values that were statistically different than the TSI 3306/3321 system and the ACI $(P=$ $.01)$. However, the magnitude of difference was small for this formulation. The other 3 solution formulations showed no statistical difference between the TSI 3306/3321 system and the ACI $(P>.01)$. One of the 2 suspension formulations, Proventil-HFA, showed no statistical difference between the TSI $3306 / 3321$ system $(P=.332)$ and the ACI. Yet, Ventolin-HFA showed a statistical difference $(P=.006)$, though this may be owing to experimental error and cannot be explained. The data illustrate that the TSI 3306/3321 system can be used in place of the ACI to determine $\mathrm{FPF}_{4.7 \mu \mathrm{m}}$ for solution and suspension MDI formulations.

\section{Particle Size}

The MMAD and GSD, which represent the measures of central tendency and spread, respectively, were used to compare the size distribution data from the Model 3321 and the ACI. When a solution MDI is actuated, the formulation is atomized into fine droplets, each containing a constant ratio of drug, propellant, and any cosolvent or excipients contained in the formulation. On the other hand, when a suspension MDI is atomized, not every droplet is uniform with respect to drug ratio. In fact, some of the atomized droplets may contain only excipient and propellant. Particle-sizing technologies, such as the TOF used with the Model 3321, which are nonspecific to chemical composition of each particle, are thus susceptible to misrepresentation of the drug particle size distribution when sizing the aerosol from an MDI suspension. ${ }^{19}$ With these physical differences in mind, it would not have been surprising to observe differences in MMAD between the TSI 3306/3321 system and ACI for suspension MDI formulations. However, Table 2 shows that, based on the current data using 4 solution and 2 suspension MDIs, the MMAD values from the ACI correlate well with
MMAD values from the TSI 3306/3321 system, when the new cut-point and $20-\mathrm{cm}$ extension are used.

Particle size values on the Model 3321 for Proventil-HFA were expected to be smaller than those for Ventolin-HFA, since Proventil-HFA contains surfactant. Yet, Table 2 shows that the values are similar, which leads to the belief that the mass of the droplets that contain only surfactant in Proventil-HFA does not cause a significantly biased measurement of the MMAD for the Model 3321.

Overall, the TSI 3306/3321 system shows similar patterns of particle distribution compared to the ACI for each of the solution and suspension formulations tested and is sufficiently sensitive to detect increases in solution concentration. Therefore, the TSI 3306/3321 system shows potential for future early development studies and may be used as a particle-sizing tool for suspension and solution MDIs of varying drug and ethanol concentrations.

\section{USP/Ph Eur Inlet}

The concentration of CSP and ethanol in the solution MDI formulations appeared to have an affect on USP/Ph Eur inlet deposition. Figure 7 shows the influence of formulation on the delivery characteristics from the CSP MDIs by comparing $\mathrm{FPF}_{4.7} \mu \mathrm{m}$ and $\mathrm{USP} / \mathrm{Ph}$ Eur inlet percentage, according to Equation 5:

$U S P / P h$ Eur Percent $=\left(\frac{U S P / P h \text { Eur }}{U S P / P h \text { Eur }+ \text { plate }+ \text { filter }}\right) \times 100$

The formulations with $3 \%$ ethanol $(\mathrm{A}, \mathrm{C})$ were much more efficient at delivering drug than the formulations with $15 \%$ ethanol (B, D) and had lower USP/Ph Eur inlet percentage and higher $\mathrm{FPF}_{4.7 \mu \mathrm{m}}$. This finding is consistent with

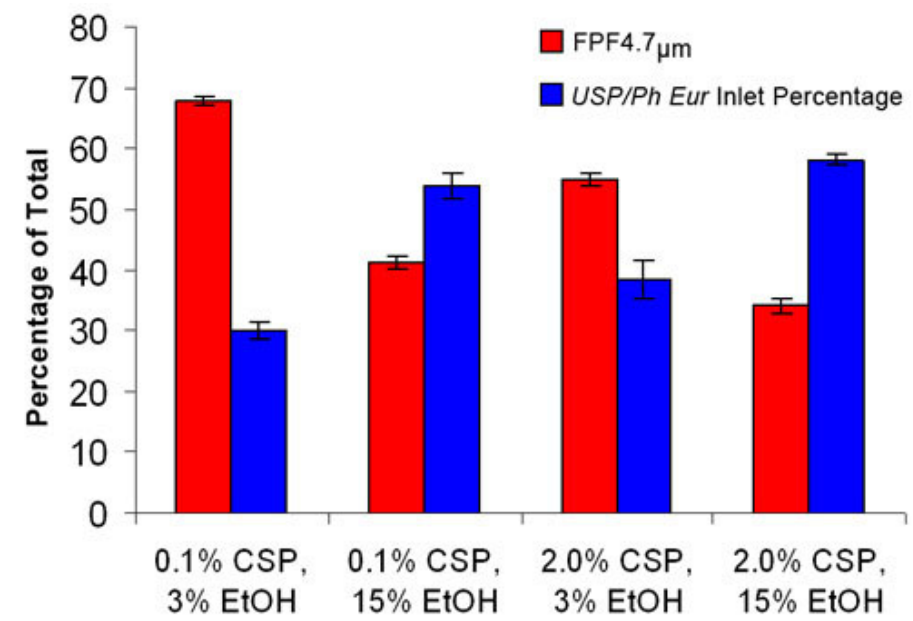

Figure 7. USP/Ph Eur inlet percentage and fine particle fraction $\left(\mathrm{FPF}_{4.7 \mu \mathrm{m}}\right)$ as a function of cyclosporin concentration using the TSI 3306/3321 system and new cut-point. 


\section{AAPS PharmSciTech 2006; 7 (1) Article 20 (http://www.aapspharmscitech.org).}

previously published literature that shows that deposition in the USP/Ph Eur induction port is inversely proportional to ethanol concentration. ${ }^{20}$ The concentration of CSP also had an influence on the delivery characteristics. The formulations with 3\% CSP had a lower $\mathrm{FPF}_{4.7 \mu \mathrm{m}}$ than the formulations with $0.1 \%$ CSP. This result was seen in 2 different situations. First, the formulations with $3.0 \%$ CSP had a larger MMAD (Table 2) and therefore had a higher fraction of aerosol larger than $4.7 \mu \mathrm{m}$. Second, the USP/Ph Eur inlet percentage increased when CSP concentration increased from $0.1 \%$ to $3.0 \%$. This difference was statistically significant, where the $P=.005$ for $3 \%$ ethanol (A vs $C$ ) and $P=.002$ for $15 \%$ ethanol (B vs $\mathrm{D}$ ). Additional research is needed to further explain this trend.

\section{CONCLUSION}

This study shows, for the first time, good agreement between the TSI 3306/3321 system and ACI for both solution and suspension MDI formulations when an adequate extension and cut-point are used. For those formulations containing higher ethanol concentrations, a $20-\mathrm{cm}$ extension may be necessary on the TSI 3306/3321 system in order to allow more time for the droplets to evaporate and to obtain particle size and $\mathrm{FPF}_{4.7 \mu \mathrm{m}}$ measurements that are in close agreement with the USP/Ph Eur standard ACI. This work indicates that the TSI 3306/3321 system is suitable for preformulation studies of both suspension and solution MDI systems.

\section{ACKNOWLEDGMENTS}

The authors would like to acknowledge TSI Inc (Shoreview, MN) for their financial support of the APS cut-point reevaluation.

\section{REFERENCES}

1. Mitchell JP, Nagel MW, Wiersema KJ, Doyle CC. Aerodynamic particle size analysis of aerosols from pressurized metered-dose inhalers: comparison of Andersen 8-stage cascade impactor, next generation pharmaceutical impactor, and model 3321 aerodynamic particle sizer aerosol spectrometer. AAPS PharmSciTech. 2003;4:E54.

2. Mogalian E, Myrdal PB. Application of USP inlet extensions to the TSI impactor system 3306/3320 using HFA 227 based solution metered dose inhalers. Drug Dev Ind Pharm.

3. Wachtel H, Zeigler J. Improved assessment of inhaler device performance using laser diffraction. Respiratory Drug Delivery VIII. 2002;2:379-381.

4. Wachtel H, Ziegler J, inventors. Laser diffraction method for particle size distribution measurements in pharmaceutical aerosols. US patent 0142665. June 30, 2005.

5. Finlay WH, Stapleton KW. Undersizing of droplets from a vented nebulizer caused by aerosol heating during transit through an Andersen impactor. J Aerosol Sci. 1999;30:105-109.

6. Ding JY, McVeety BD, Busick DR, Miller PR, Zimlich WC, Placke ME. Correlation of particle size distribution measurements between optical and inertial impaction techniques using an ethanolic drug formulation for inhalation. Respiratory Drug Delivery VIII. 2002;2:355-358.

7. Holmes CE, Kippax PG, Newell HE, Southhall JP, Ward DJ. Simultaneous analysis of respirable aerosols via laser diffraction and cascade impaction. Drug Delivery to the Lungs XII. London, UK; The Aerosol Society; 2001;58-61.

8. Smyth HDC, Hickey AJ. Comparative particle size analysis of solution propellant driven metered dose inhalers using cascade impaction and laser diffraction. Respiratory Drug Delivery VIII. 2002;2:731-734.

9. Haynes A, Shaik MS, Krarup H, Singh M. Evaluation of the Malvern Spraytec with inhalation cell for the measurement of particle size distribution from metered dose inhalers. J Pharm Sci. 2004;93:349-363.

10. Corcoran TE, Hitron R, Humphrey W, Chigier N. Optical measurement of nebulized sprays: a quantitative comparison of diffraction, phase Doppler interferometry, and time-of-flight analysis. J Aerosol Sci. 2000;31:35-50.

11. Stein SW, Gabrio BJ, Oberreit D, Hairston P, Myrdal PB, Beck TJ. An evaluation of mass-weighted size distribution measurements with the model 3320 aerodynamic particle sizer. J Aerosol Med. 2003;16:107-119.

12. Myrdal PB, Stein SW, Mogalian E, Hoye WL, Gupta A. Comparison of the TSI model 3306 impactor inlet with the Andersen cascade impactor: solution metered dose inhalers. Drug Dev Ind Pharm. 2004;30:859-868.

13. Marple VA. A Fundamental Study of Inertial Impactors. Minneapolis, MN: University of Minnesota, Particle Technology Laboratory-Publication 144;1970.

14. Hinds WC. Aerosol Technology. New York, NY: John Wiley \& Sons; 1999.

15. Rader DJ, Marple VA. A study of the effects of anisokinetic sampling. Aerosol Sci Technol. 1988;8:283-299.

16. Hickey AJ, Dalby RN, Byron PR. Effects of surfactants on aerosol powders in suspension: implications for airborne particle size. Int J Pharm. 1988;42:267-270.

17. Vaughan NP. The Andersen impactor: calibration, wall losses and numerical simulation. J Aerosol Sci. 1989;20:67-90.

18. Stein SW, Olson BA. Variability in size distribution measurements obtained using multiple Andersen mark II cascade impactors. Pharm Res. 1997;14:1718-1725.

19. Stein SW, Myrdal PB. A theoretical and experimental analysis of formulation and device parameters affecting solution MDI size distributions. J Pharm Sci. 2004;93:2158-2175.

20. Gupta A, Stein SW, Myrdal PB. Balancing ethanol cosolvent concentration with product performance in 134a-based pressurized metered dose inhalers. J Aerosol Med. 2003;16:167-174. 